Article

\title{
Study on Behavior of the Heat Exchanger with Conically-Corrugated Tubes and HDD Baffles
}

\author{
Zhiwei $\mathrm{Wu}^{*}$ and Caifu Qian \\ Institute of Mechanical and Electrical Engineering, Beijing University of Chemical Technology, \\ Beijing 100029, China; qiancf@mail.buct.edu.cn \\ * Correspondence: zwzhiweiwu@163.com
}

\begin{abstract}
Baffles with holes in different diameters (or HDD baffles) and conically-corrugated tubes are respectively longitudinal flow baffle and high-efficiency heat exchange tubes proposed by the author. In this paper, vibrations of tube bundles with HDD baffles and fluid flow as well as heat transfer inside conically-corrugated tubes were numerically simulated, and the heat exchanger with conically-corrugated tubes and HDD baffles was tested for the heat transfer efficiency. It is found that compared with the traditional segmental baffles, tube bundle vibrations in heat exchangers, if using the HDD baffles, can be significantly reduced. Regarding heat transfer efficiency, conicallycorrugated tubes are much better than smooth tubes and even better than other high-efficiency heat transfer tubes. Compared with the traditional heat exchangers, heat exchangers constructed with conically-corrugated tubes and the HDD baffles can provide better heat transfer efficiency and less tube bundle vibration.
\end{abstract}

Keywords: heat exchanger; tube bundle vibration; high-efficiency heat transfer; numerical simulation

Citation: Wu, Z.; Qian, C. Study on Behavior of the Heat Exchanger with Conically-Corrugated Tubes and HDD Baffles. ChemEngineering 2022, 6,1. https://doi.org/10.3390/ chemengineering6010001

Academic Editor: Alírio E. Rodrigues

Received: 3 November 2021 Accepted: 30 December 2021 Published: 2 January 2022

Publisher's Note: MDPI stays neutral with regard to jurisdictional claims in published maps and institutional affiliations.

Copyright: (c) 2022 by the authors. Licensee MDPI, Basel, Switzerland. This article is an open access article distributed under the terms and conditions of the Creative Commons Attribution (CC BY) license (https:// creativecommons.org/licenses/by/ $4.0 /)$.

\section{Introduction}

Shell and tube heat exchangers are widely used in the petrochemical industry, manufacturing industry, power production, and energy-saving system because of their simple structure, low cost, and strong design adaptability [1-4]. The shell-side fluid of the traditional segmental baffle heat exchanger flows transversely perpendicular to the tube bundle under the guidance of the segmental baffle, forming a heat transfer dead zone near the baffle [5]. At the same time, due to the transverse scouring of the tube bundle by the fluid, it is easy to stimulate fluid-induced vibration and cause damage [6]. The longitudinal flow heat exchanger changes the shell side fluid from the transverse flow perpendicular to the tube bundle to the longitudinal flow along the tube bundle, which not only eliminates the heat transfer dead zone and makes effective use of the heat transfer surface, but also effectively reduces the tube bundle vibration and improves the safety of the heat exchanger [7].

Flow-induced vibration of tube bundle plays an important role in heat exchanger failure. At present, there are mature theoretical systems and engineering experience for tube bundle vibration induced by single-phase fluid transverse flow [8]. Ji et al. [9] studied the flow-induced vibration response of the shell side of a heat exchanger and the heat transfer characteristics of elastic tube bundles by a two-way fluid-structure coupling method. The results showed that the shell-side fluid mainly causes the out-of-plane vibration of the tube bundle. At the same time, the tube bundle vibration can enhance the heat transfer performance of the shell side at low Reynolds number. Mahmoud et al. [10] studied the vibration characteristics of three non-uniform spaced cylinders in cross-flow at low Reynolds number by numerical simulation. The results show that the non-uniform spacing between cylinders will lead to significant changes in the flow characteristics of rear cylinders. In addition, with the increase of velocity, the downstream cylinder oscillates with higher amplitude until it reaches the maximum and then decreases gradually. Duan et al. [11] studied the flow-induced vibration enhanced heat transfer of plane elastic tube 
bundles by a two-way fluid-structure coupling method and investigated the effects of tube wall thickness, tube spacing, and tube row spacing on enhanced heat transfer. Finally, an empirical correlation for predicting flow-induced vibration enhanced heat transfer of plane elastic tube bundles is obtained. Khan et al. [12] established a two-dimensional numerical model of flow-induced vibration of heat exchanger tube bundle under cross flow. The vortex shedding frequency is predicted by Fourier transform using the lift coefficient diagram obtained from the analysis. The experimental results of St and tube natural frequency are verified numerically. Ishihara et al. [13] tested the actual heat exchanger to investigate the causes of tube vibration. The results showed that the tube chattering is caused by the turbulence caused by the gap between the heat exchange tube and the baffle.

HDD baffles are a new type of tube bundle support structure proposed by the author $[14,15]$. On the baffle, there are large and small holes. The shell-side fluid flows through the gap between the large holes and the heat exchange tubes, forming wall jet flow. The small holes support the tube bundle for the horizontal heat exchangers. The large and small circular holes on the adjacent two baffles are alternately distributed. With HDD baffles, shell-side fluid flow in heat exchangers is longitudinal along tubes rather than the transverse in traditional heat exchangers with segmental baffles. Compared with other common special-shaped orifice baffles (trefoil-hole [16], quatrefoil-hole [17], and plum blossom-hole plate [18], etc.), it has the advantages of simple processing and low cost. Maakoul et al. [19] compared the effects of trefoil-hole, helical and segmental baffles on fluid flow and heat transfer in the shell side of shell and tube heat exchanger through numerical simulation. It is found that the helical baffle heat exchanger has higher thermal and hydraulic performance, and the trefoil-hole baffle heat exchanger has higher heat transfer performance and higher pressure drop. Ma et al. [20] compared and studied the shell-side fluid flow and heat transfer performance of trefoil-hole and quatrefoil-hole baffle heat exchangers through numerical simulation. It is found that compared with quatrefoil-hole baffle heat exchanger, trefoil-hole baffle heat exchanger has a higher heat transfer coefficient under unit pressure drop. Sun et al. [21] conducted experimental and numerical studies on the flow characteristics and heat transfer performance of the heat exchanger with baffles with holes in different diameters. The results show that the pressure drop on the shell side is greatly reduced because the fluid on the shell side changes from transverse flow to longitudinal flow. Under the same pressure drop on the shell side, the heat transfer coefficient of the heat exchanger with HDD baffles is $25 \%$ higher than that of the traditional segmental heat exchanger. Liu et al. [22] studied the fluid flow and heat transfer performance of six shell and tube heat exchangers by experimental and numerical simulation methods. The results show that compared with the traditional segmental baffle heat exchanger, the heat exchanger with arc-corrugated tubes and HDD baffles has better comprehensive heat transfer performance. Conically-corrugated tube is also a new type of high-efficiency heat exchange tube proposed by the author [23]. The difference between it and corrugated tube is that a straight edge section is introduced between wave crest and wave trough, which is tangent to wave crest arc and wave trough arc, respectively.

As new components, there are few systematic studies on the vibration analysis of heat exchangers with HDD baffle and the fluid flow and heat transfer performance inside the conically-corrugated tubes. In this paper, the tube bundle vibration when using HDD baffles in a heat exchanger will be numerically simulated and compared with that when applying traditional segmental baffles. Fluid flow and heat transfer performance inside conically-corrugated tubes will be conducted and compared with other high-efficiency heat transfer tubes. In addition, a new heat exchanger will be constructed with conicallycorrugated tubes and HDD baffles. Experiments will be carried to study the heat transfer behavior in the equipment to find its advantages over the traditional heat exchanger.

\section{Vibration Reduction of the Tube Bundle with HDD Baffles}

In this section, tube bundle vibration in heat exchangers with different baffles were examined numerically with a fluid-structure coupling approach. Three finite element 
models were established. One is using traditional segmental baffles with the height of the segmental cut of $25 \% \mathrm{D}$ where the shell-side fluid flow is transverse. The second is using HDD baffles without the segmental cut where the shell-side fluid flow is longitudinal. The third is using HDD baffles with the height of the segmental cut of $25 \% \mathrm{D}$ where the shell-side fluid flow is cross flow having both transverse and longitudinal components. Fluent module and Transient Structural module with Ansys Workbench 18.0 are were applied respectively for the fluid dynamic and transient dynamic analysis.

Figure 1 shows the three-dimensional model of the heat exchangers with HDD baffles. Detailed structural parameters are listed in Table 1. The other two models are the same except for the structure of the baffles, as shown in Figure 2. Considering the difficulties in fluid-structure coupling computation and the mutual influence of the adjacent tube vibration, nine tubes in the middle of the exchanger were treated to be elastic while others were set to be rigid without deformation while having geometrical boundaries. Shell elements were used to mesh the tubes.

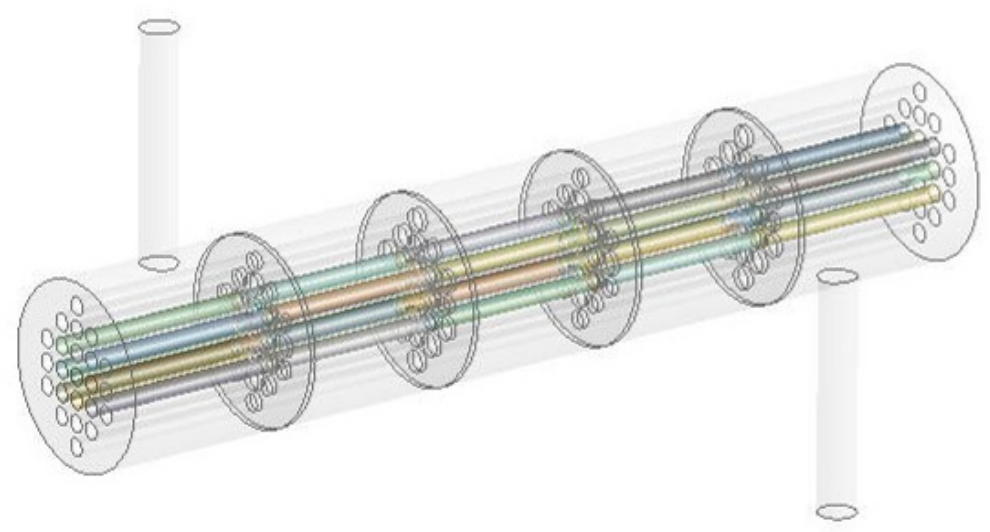

Figure 1. Three-dimensional model of the heat exchangers with HDD baffles.

(a)

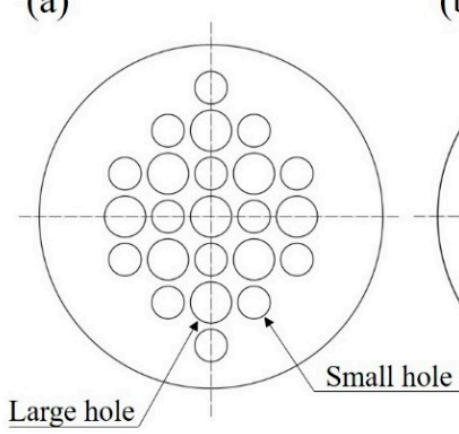

(b)

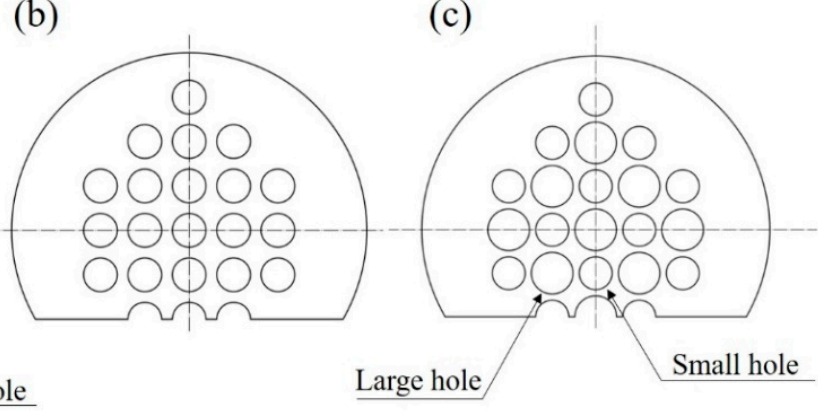

Figure 2. Schematic structure of baffles: (a) HDD baffles; (b) segmental baffles (25\%D); (c) segmental HDD baffles $(25 \% \mathrm{D})$. 
Table 1. Structural parameters of the heat exchangers with HDD baffles.

\begin{tabular}{cc}
\hline Structural Parameters & Size or Property \\
\hline Inner diameter of the shell $(\mathrm{mm})$ & 200 \\
Length of the shell $(\mathrm{mm})$ & 1034 \\
Diameter of inlets and outlets on the shell $(\mathrm{mm})$ & 40 \\
Number of tubes & 23 \\
Arrangement of tubes & Rectangular \\
Spacer of tubes $(\mathrm{mm})$ & 25 \\
Diameter of large holes $(\mathrm{mm})$ & 24 \\
Spacer of baffles $(\mathrm{mm})$ & 194 \\
Thickness of the baffles $(\mathrm{mm})$ & 6 \\
Outside diameter of the tube $(\mathrm{mm})$ & 19 \\
Thickness of the tube $(\mathrm{mm})$ & 2 \\
\hline
\end{tabular}

For the boundaries, two ends of the tubes were fixed. As actual clearances exist between the tube holes and the tubes, no supports of the baffles on the tube vibration were considered in this analysis for conservative modeling. The contact faces between tube walls and shell-side fluid domain were set to be the contact surface of FSI. The inlet and outlet adopted velocity inlet and pressure outlet, respectively. After performing mesh independence tests, the final models had about 2,165,000 nodes and 766,430 elements. For the transient computation, the time step of 0.001 was applied.

Figure 3 shows the grid model of the heat exchangers with HDD baffles and Figure 4 shows the grid model of the tube bundle.

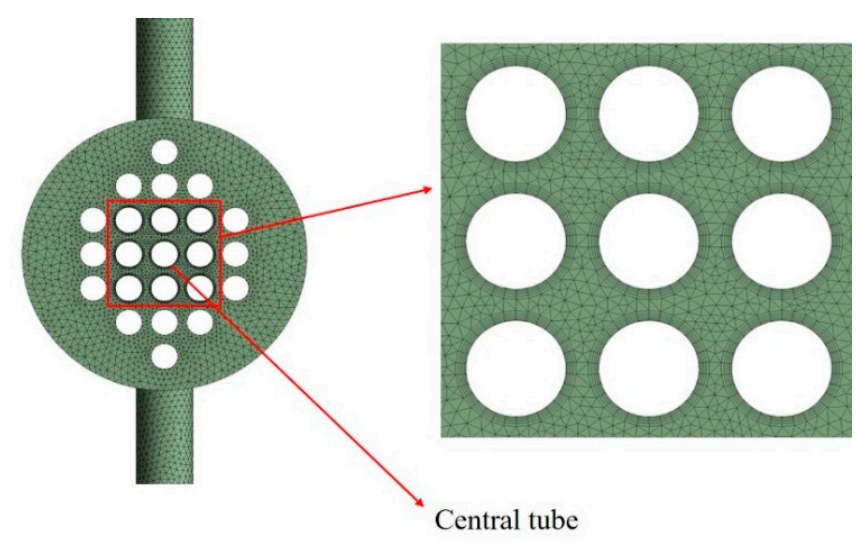

Figure 3. Grid model of the heat exchanger with HDD baffles.

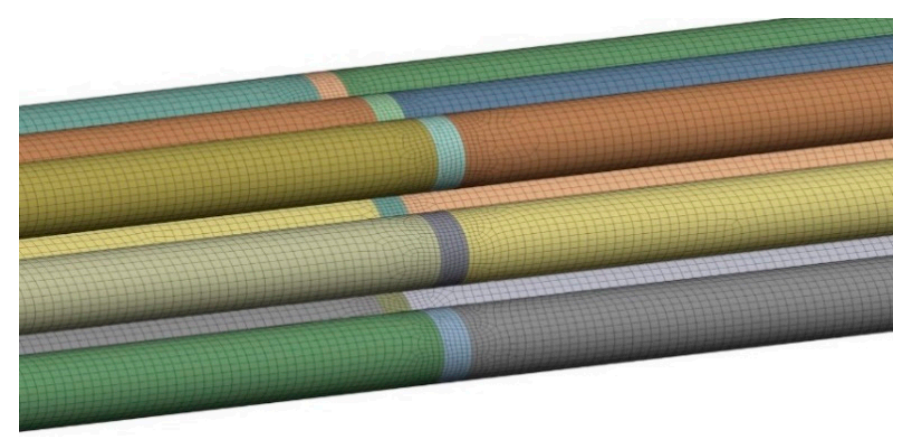

Figure 4. Grid model of the tube bundle.

As mentioned before, tube vibrations will mutually influence the tube bundle induced by shell-side fluid flow. In order to mostly reflect the real situation, the tube at the center of the tube bundle in Figure 4 was focused. Figure 5 shows the vibrations at the middle of the tube for different models in the time domain. Clearly for the three baffles, the vibration of 
the tube bundle with the traditional segmental baffles is much larger than that of the tube bundle with HDD baffles without the segmental cut. As it also has some transverse flow, the vibration of the tube bundle with HDD baffles have a segmental cut that is also larger than that of the tube bundle with HDD baffles without a segmental cut.

The root-mean-square of the acceleration of vibration can be better reflect the serious the vibration [24]. For the three vibrations in Figure 5, the root-mean-squares of the acceleration are $1.5035 \mathrm{~mm}^{2} / \mathrm{s}, 1.1830 \mathrm{~mm}^{2} / \mathrm{s}$, and $0.9494 \mathrm{~mm}^{2} / \mathrm{s}$, respectively, for traditional segmental baffles, HDD baffles with the segmental cut, and HDD baffles without the segmental cut. Clearly, the root-mean-square of the acceleration for HDD baffles without the segmental cut is the smallest, meaning that using HDD baffles, the tube bundle vibration can be significantly reduced.

Figure 6 shows the vibrations in the frequency domain. It is found that all the tube bundles with the three types of baffles are vibrated at low frequency. It turns out by performing model analysis that the first natural frequency of the tube is about $100 \mathrm{~Hz}$. Figure 6 shows a small bounce in amplitude at this frequency.

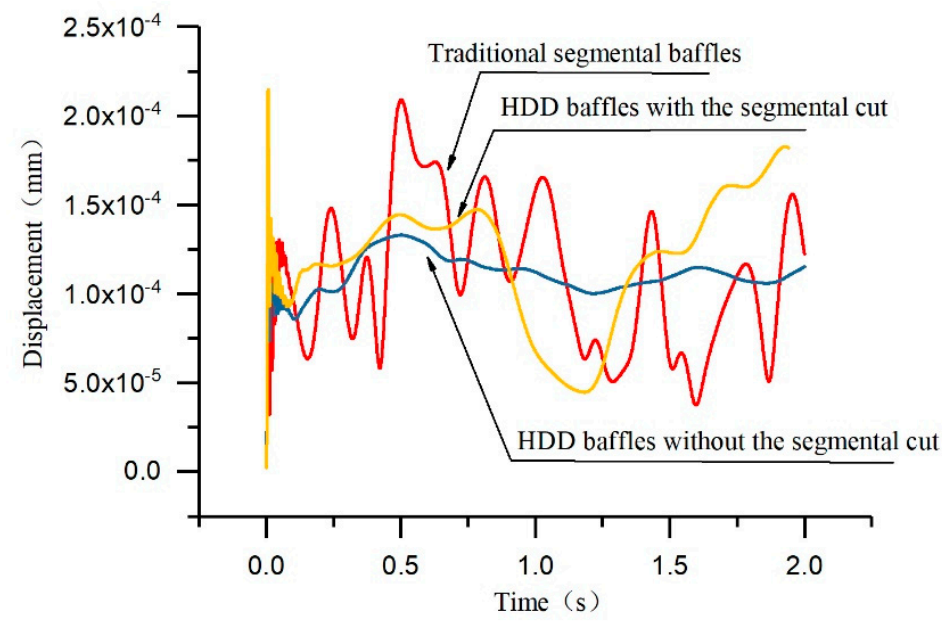

Figure 5. Vibration signal of the central tube in the time domain.

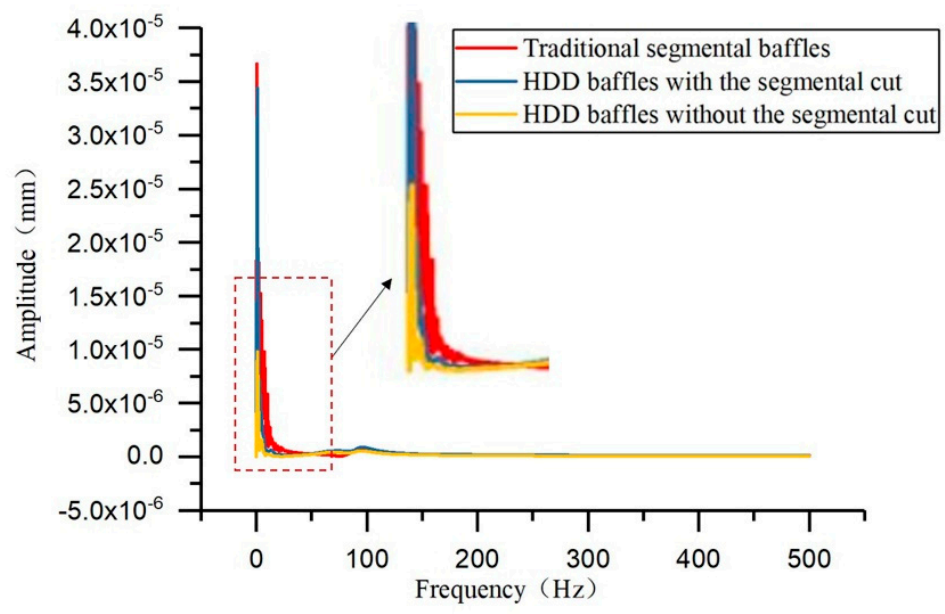

Figure 6. Vibration signal of the central tube in the frequency domain.

\section{Heat Transfer Enhancement with Conically-Corrugated Tubes}

Developing high-efficient heat transfer tubes has always been a hot issue for heat transfer enhancement. By rolling into different surface structures from the base smooth tubes, several profile tubes are used in engineering. Conically-corrugated tube is a new shape of high-efficiency heat transfer tube developed by the author. Figure 7 illustrates the structure of the conically-corrugated tube which is one used in the heat exchanger for the 
experiments in Section 4. In this section, fluid flow and heat transfer inside the conicallycorrugated tube were numerically simulated and compared with other high-efficiency heat transfer tubes and smooth tubes.

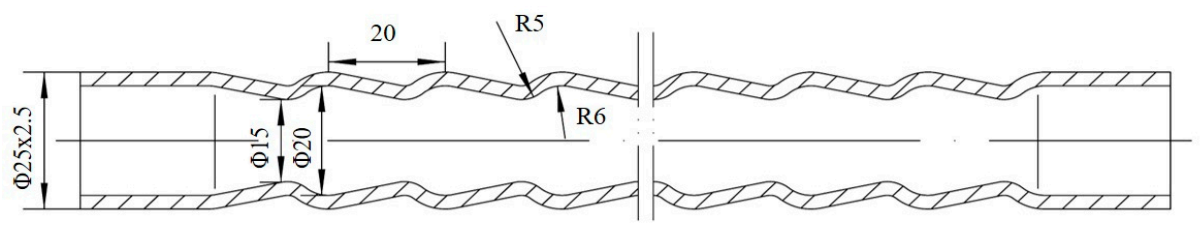

Figure 7. Illustration of the Structure of conically-corrugated tube.

Figure 8 shows the three-dimensional geometrical models of the high-efficiency heat transfer tubes including conically-corrugated tube, arc-corrugated tube, convergentdivergent tube, and spiral grooved tube. Figures 9-12 show the grid models with the specific structural details for high-efficiency heat transfer tubes, which take the common structural parameters. At the same time, the pitch of the arc-corrugated tubes and convergent-divergent tubes is the same as that of the conically-corrugated tubes.

(a)

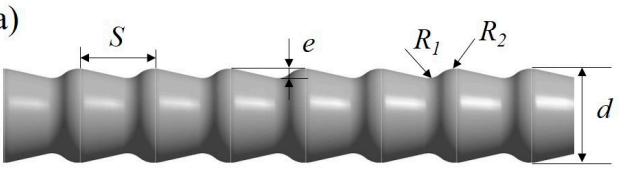

(c)

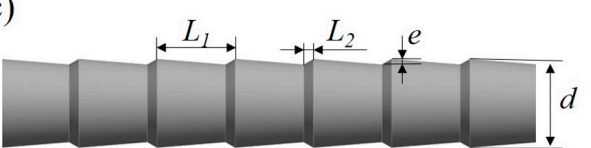

(b)

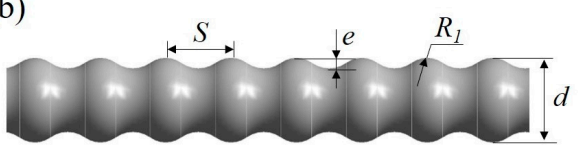

(d)



Figure 8. Three-dimensional geometrical models: (a) conically-corrugated tube; (b) arc-corrugated tubes; (c) convergent-divergent tube; (d) spiral grooved tube.
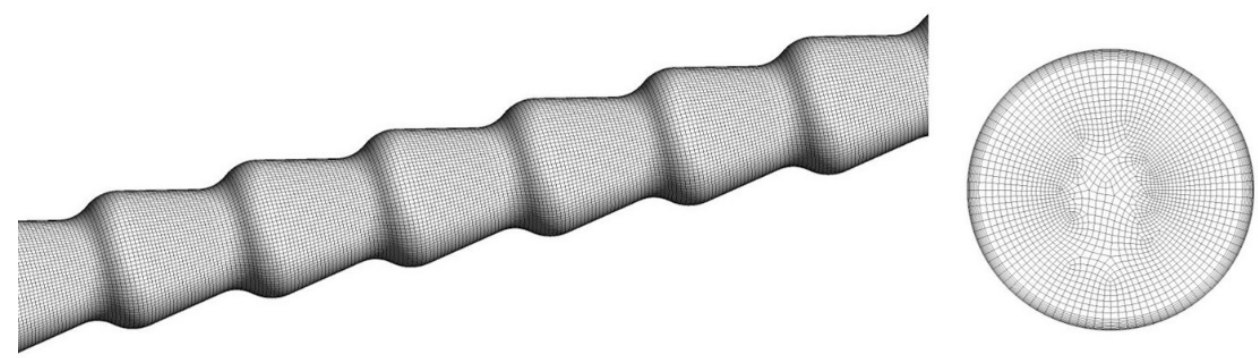

Figure 9. Grid model of the conically-corrugated tube $(d=20 \mathrm{~mm}, L=300 \mathrm{~mm}, t=2.5 \mathrm{~mm}, e=2.5 \mathrm{~mm}$, $\left.R_{1},=5 \mathrm{~mm}, R_{2},=6 \mathrm{~mm}\right)$.
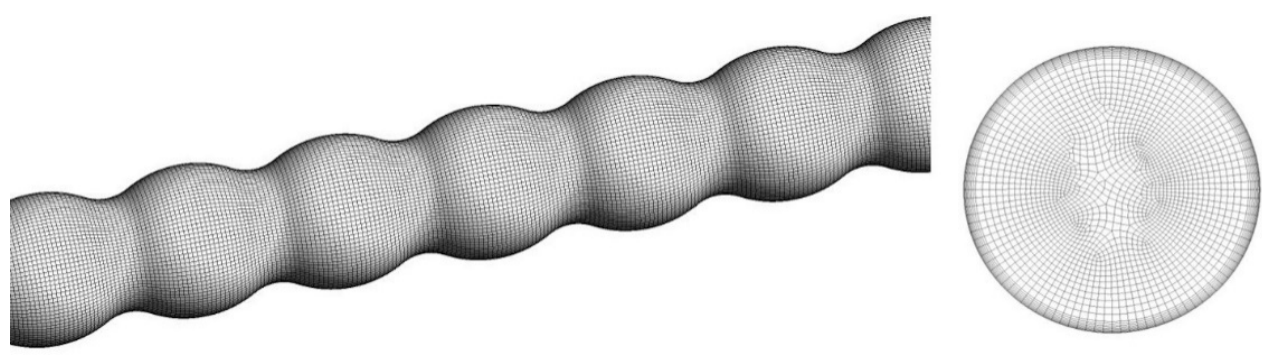

Figure 10. Grid model of the arc-corrugated tube $(d=20 \mathrm{~mm}, L=300 \mathrm{~mm}, t=2.5 \mathrm{~mm}, e=2.5 \mathrm{~mm}$, $\left.R_{1},=15 \mathrm{~mm}\right)$. 

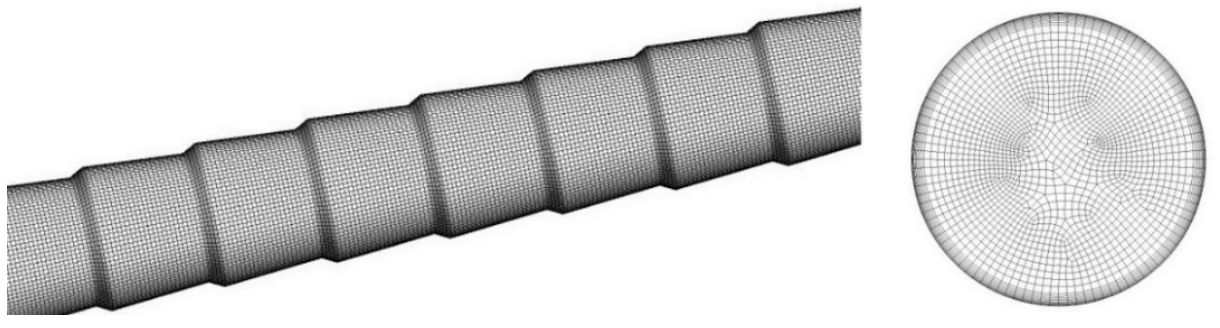

Figure 11. Grid model of the convergent-divergent tube $\left(d=20 \mathrm{~mm}, L=300 \mathrm{~mm}, L_{1},=20 \mathrm{~mm}\right.$, $L_{2,}=2.5 \mathrm{~mm}, t=2.5 \mathrm{~mm}$ ).
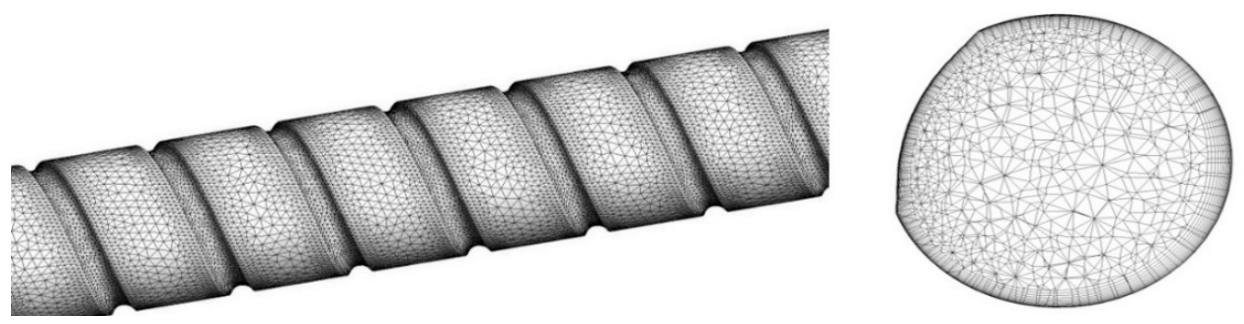

Figure 12. Grid model of the spiral grooved tube $(d=20 \mathrm{~mm}, L=300 \mathrm{~mm}, P=13 \mathrm{~mm}, W=3 \mathrm{~mm}$, $e=1 \mathrm{~mm}$ ).

In this section, the commercial software ANSYS fluent 18.0 was used to simulate the fluid flow and heat transfer in the tubes. The standard turbulence model and scalable wall function were used. The governing equations were solved by SIMPLE algorithm. The pressure term was discretized by the standard scheme, and other variables were discretized by the second-order upwind scheme. The convergence criterion was that the energy residual curve reaches $10^{-6}$ and the other variables were $10^{-4}$. The boundary conditions of velocity inlet and pressure outlet were adopted, and the outlet pressure was set to zero, so the inlet pressure was the tube side pressure drop. The inlet fluid and tube wall temperatures were $323 \mathrm{k}$ and $293 \mathrm{k}$, respectively. See Table 2 for physical parameters of water. Taking the conically-corrugated tube as an example, the grid independence verification was carried out to ensure the accuracy of numerical research. The results are shown in Table 3. Three groups of meshes are listed in the table. Through mesh refinement, the Nusselt number and resistance coefficient tends to be stable, and the relative error is less than $2 \%$. Therefore, considering the calculation difficulty, the grid of 2,032,574 nodes is used for division.

Table 2. Physical properties parameter of water.

\begin{tabular}{cc}
\hline Parameter & Value \\
\hline$c p$ & $4174, \mathrm{~J} \mathrm{~kg}^{-1} \cdot \mathrm{K}^{-1}$ \\
$\mu$ & $0.000601, \mathrm{~kg} \mathrm{~m}^{-1} \cdot \mathrm{s}^{-1}$ \\
$\rho$ & $990.2, \mathrm{~kg} \cdot \mathrm{m}^{-3}$ \\
$\lambda$ & $0.642, \mathrm{Wm}^{-1} \cdot \mathrm{K}^{-1}$ \\
\hline
\end{tabular}

Table 3. Verification of mesh independence of the conically-corrugated tube.

\begin{tabular}{ccccc}
\hline Number of Nodes & $\mathbf{N u}$ & Relative Error (\%) & $f$ & Relative Error (\%) \\
\hline 3060590 & 140.603 & 0 & 0.2596 & 0 \\
2067268 & 140.5816 & 0.02 & 0.2628 & 1.2 \\
1059240 & 141.089 & 0.3 & 0.2762 & 6.4 \\
\hline
\end{tabular}


In the heat exchanger area, the mean Nusselt number and friction coefficient are two important parameters. The former reflects heat transfer efficiency, and the latter indicates the flow resistance. Figure 13a shows the mean Nusselt numbers changing with Reynolds number for different heat transfer tubes. It is found that the mean Nusselt number for conically-corrugated tubes were $110-130 \%$ larger than smooth tube and 11-17 and $26 \%$ larger than the high-efficiency spiral grooved tube and convergent-divergent tube, indicating conically-corrugated tube is the most for heat transfer enhancement. Figure 13b shows friction coefficients changing with Reynolds number for different heat transfer tubes. As the cross section of the tube is constantly changing, all the friction coefficients of highefficiency tubes are larger than that of the smooth tubes, meaning that the flow resistances inside high-efficiency tubes are raised compared with smooth tubes. But it is noted that enhancing heat transfer is the first consideration in the design of heat exchangers. At the same time, it is seen that the resistance coefficient of the conically-corrugated tube is lower than that of the arc-corrugated tube, which implies that the conically-corrugated tube has better comprehensive performance.

(a)

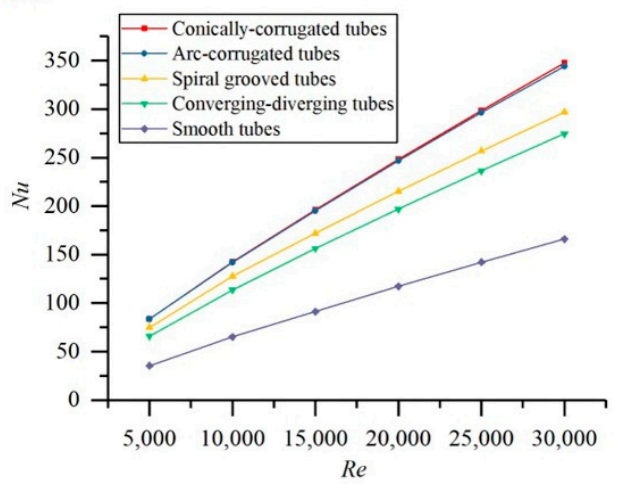

(b)

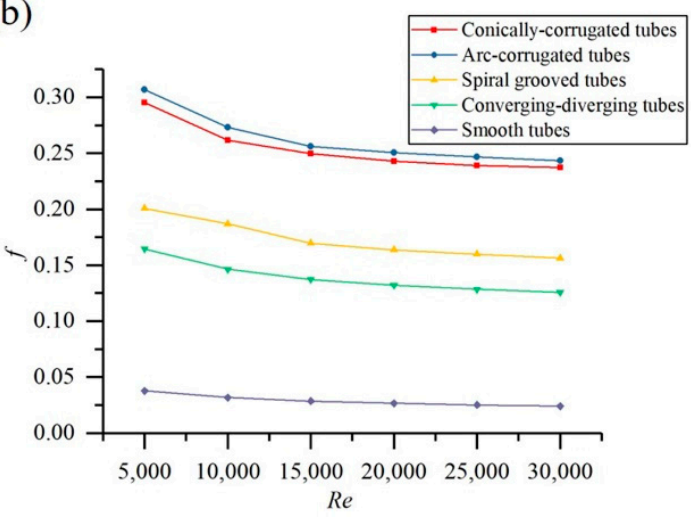

Figure 13. Mean Nusselt number and friction coefficient changing with Reynolds number for different tubes: (a) mean Nusselt number; (b) friction coefficient.

\section{Heat Transfer Behavior of the Heat Exchanger with Conically-Corrugated Tubes and HDD Baffles}

In this section, a heat exchanger constructed with conically-corrugated tubes and HDD baffles was tested to investigate the heat transfer behavior [25]. The conically-corrugated tube was rolled from a smooth tube (base tube). Referring to Figure 7, the outside diameter $d$ of the base tube was $25 \mathrm{~mm}$; the thickness of the tube was $2.5 \mathrm{~mm}$; the arc radius at the trough $R_{1},=5 \mathrm{~mm}$; the arc radius at the peak $R_{2},=6 \mathrm{~mm}$; and the pitch $S=20 \mathrm{~mm}$. Other structural parameters of the heat exchanger are listed in Table 4 . It should be pointed out that heat exchange tubes with an outside diameter $25 \mathrm{~mm}$ were most commonly used to construct shell-and-tube heat exchangers in chemical engineering. Selection of the heat exchange area, which determines the number and length of tubes or the diameter of the shell mainly of the tested heat exchanger, depends on the capability of the experimental system. Figure 14 shows the conically-corrugated tube bundle of the exchanger. For comparison, a heat exchanger with smooth tubes and traditional segmental baffles was also manufactured and tested. The test medium was water with the properties listed in Table 2. 
Table 4. Structural parameters of heat exchanger with conically-corrugated tubes and HDD baffles.

\begin{tabular}{cc}
\hline Structural Parameters & Size or Property \\
\hline Inner diameter of the shell $(\mathrm{mm})$ & 300 \\
Length of the shell $(\mathrm{mm})$ & 2847 \\
Diameter of inlets and outlets on the shell $(\mathrm{mm})$ & 50 \\
Number of tubes & 32 \\
Arrangement of tubes $(\mathrm{mm})$ & Rectangular \\
Spacer of tubes $(\mathrm{mm})$ & 32 \\
Diameter of large holes $(\mathrm{mm})$ & 29 \\
Spacer of baffles $(\mathrm{mm})$ & 194 \\
Height of the cut segment of the baffles $(\mathrm{mm})$ & 60 \\
Thickness of the baffles $(\mathrm{mm})$ & 4 \\
Number of tube pass $(\mathrm{mm})$ & 2 \\
Number of shell pass $(\mathrm{mm})$ & 1 \\
\hline
\end{tabular}

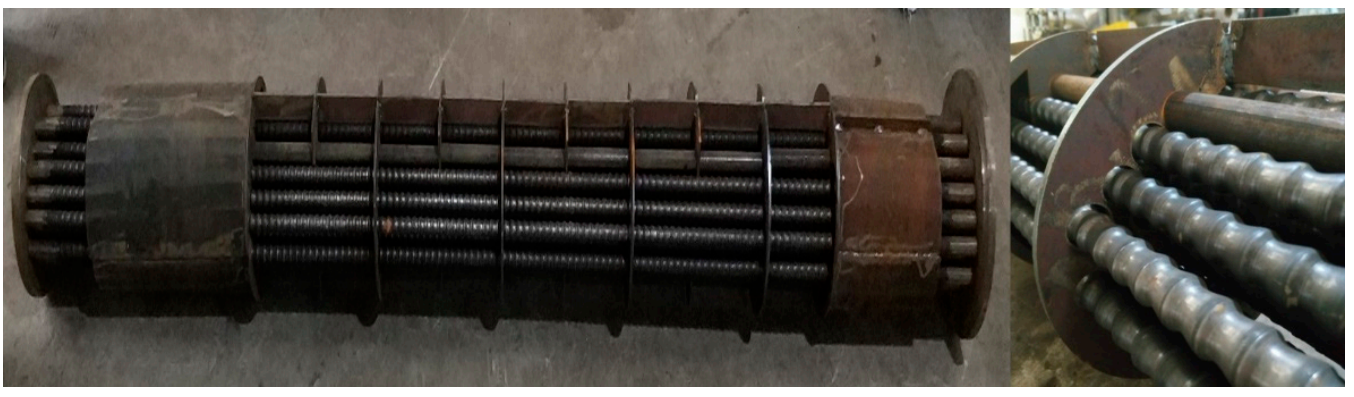

Figure 14. Conically-corrugated tube bundle for the test.

The experimental device is schematically shown in Figure 15. After being heated to the target temperature (about $70^{\circ} \mathrm{C}$ ) by the electric heater, the hot water in the hot water tank was pumped into the shell-side inlet of the heat exchanger. The cold water in the cold-water tank was also heated to the target temperature (about $30^{\circ} \mathrm{C}$ ) and then pumped into the tube-side inlet of the heat exchanger. The cold and hot fluids conducted heat exchange inside the heat exchanger, which is a double tube-side heat exchanger. During the tests, the flow rate on the shell or tube side was fixed while changing the flow rate on the other side. The tube-side flow rate and shell-side flow rate are $4.02 \mathrm{~m}^{3} / \mathrm{h}-21.18 \mathrm{~m}^{3} / \mathrm{h}$ and $6.09 \mathrm{~m}^{3} / \mathrm{h}-$ $45 \mathrm{~m}^{3} / \mathrm{h}$, respectively. In these ranges, the Reynolds number of the tube-side fluid was about 5000-30,000, and that of shell-side fluid was about 8000-60,000. By measuring temperatures at the inlets and outlets on both shell and tube sides and calculating the heat $Q$ transferred and the temperature difference $\Delta t_{m}$, the total heat transfer coefficient $K$ can be evaluated as:

$$
K=\frac{Q}{A \Delta t_{m}}
$$

where $A$ is the heat transfer area.

Figure 16 shows the total heat transfer coefficient changing with the tube-side flow rate while keeping the shell-side flow rate be constant as $45 \mathrm{~m}^{3} / \mathrm{h}$. It was found that compared with the heat exchanger with smooth tubes and traditional segmental baffle, the total heat transfer coefficient of the heat exchanger constructed with conically-corrugated tubes and HDD baffles was increased by 30-66\%. Figure 17 shows the total heat transfer coefficient changing with the shell-side flow rate while keeping the tube-side flow rate be constant as $26.26 \mathrm{~m}^{3} / \mathrm{h}$. It was found that compared with the traditional heat exchanger, the total heat transfer coefficient of the heat exchanger with conically-corrugated tubes and HDD baffles is increased by $9-18 \%$. 


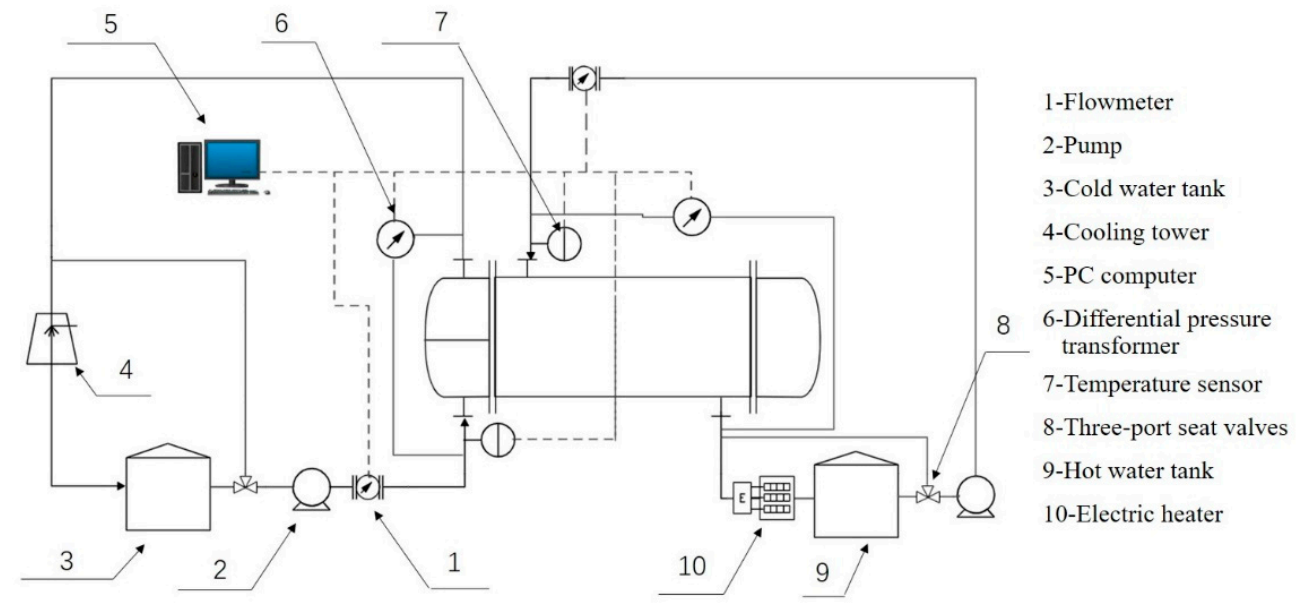

Figure 15. Schematic diagram of the experimental device.

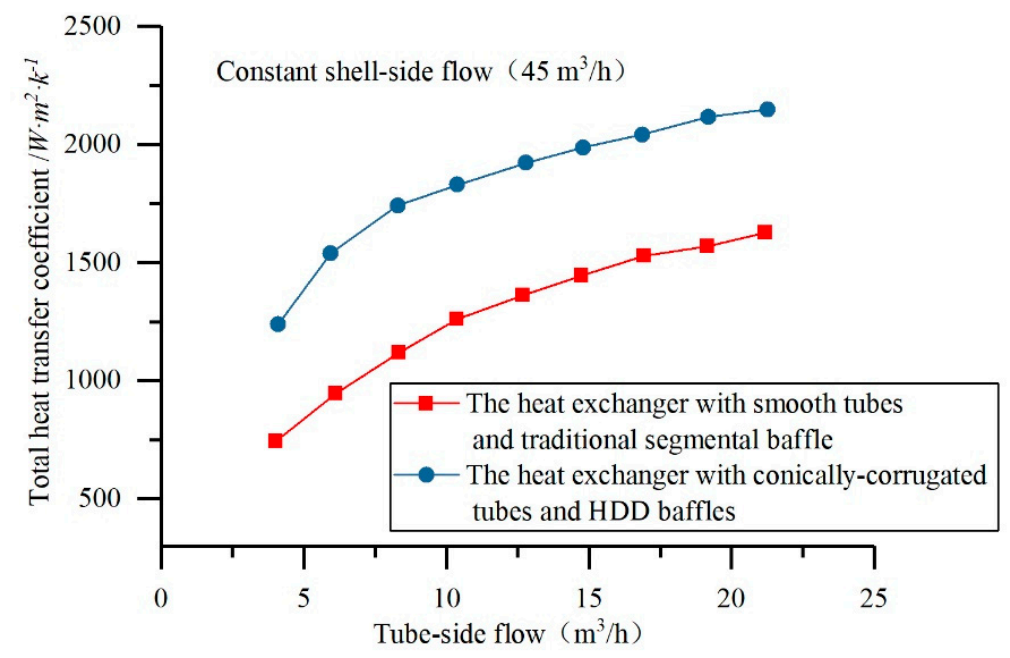

Figure 16. Total heat transfer coefficient changing with tube-side flow rate while keeping the shell-side flow rate constant.

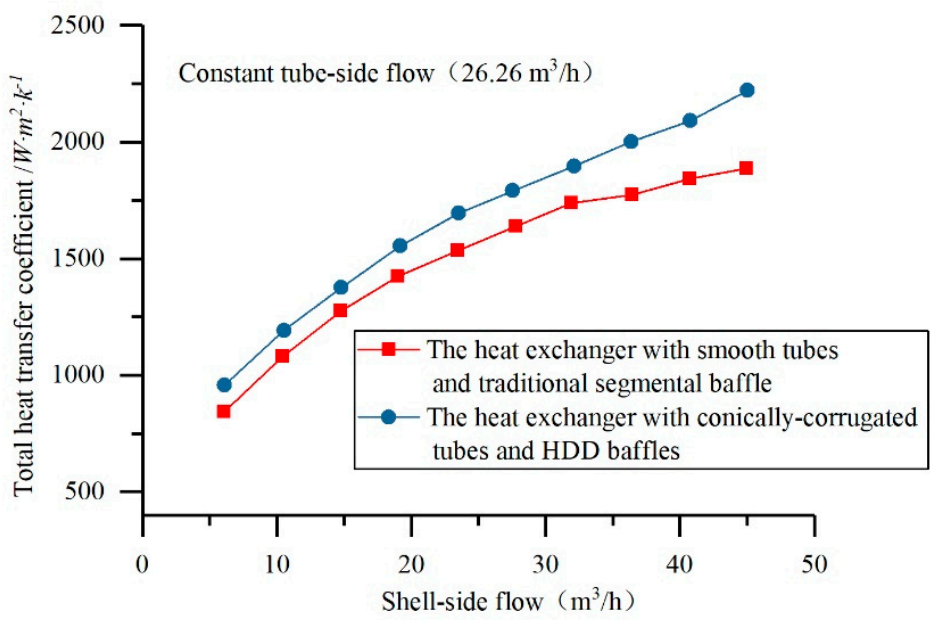

Figure 17. Total heat transfer coefficient changing with shell-side flow rate while keeping the tube-side flow constant. 
From the above analysis, it was determined that if the heat exchanger is constructed with conically-corrugated tubes and HDD baffles, not only the tube bundle can be significantly reduced, but also the heat transfer efficiency can be remarkably increased.

\section{Conclusions and Discussion}

In this paper, vibrations of tube bundles with HDD baffles and fluid flow as well as heat transfer inside conically-corrugated tubes were numerically simulated and the heat exchanger with conically-corrugated tubes and HDD baffles were tested for the heat transfer efficiency. The main conclusions are drawn as follows.

(1) Compared with the traditional segmental baffles, tube bundle vibrations in heat exchangers using the HDD baffles can be significantly reduced.

(2) Regarding heat transfer efficiency, conically-corrugated tubes are much better than smooth tubes and even better than other high-efficiency heat transfer tubes. Specifically, its average Nusselt number is $11-17 \%, 26 \%$, and $110-130 \%$ higher than that of spiral grooved tubes, convergent-divergent tubes, and smooth tubes, respectively. In addition, the resistance coefficient of conically-corrugated tubes was lower than that of arc-corrugated tubes.

(3) Experiments found that compared with the traditional heat exchangers, heat exchangers with conically-corrugated tubes and the HDD baffles can provide a large total heat transfer coefficient, i.e., better heat transfer efficiency. Specifically, in the range studied here, the total heat transfer coefficient of the heat exchanger with conically-corrugated tube and HDD baffle was 9-18\% higher than that of the traditional segmental baffle when the tube side flow is kept constant.

It should be pointed out that both conically-corrugated tubes and HDD baffles are new components in shell-and-tube heat exchangers. So the novelty of the work is mainly to provide a new shell-and-tube heat exchanger constructed with conically-corrugated tubes and HDD baffles and has a higher efficiency heat transfer and less tube bundle vibration. But more studies and results are needed for the assessments and improvements in heat transfer of the heat exchanger studied here, including providing correlated equations for the heat transfer coefficients and friction coefficients of fluid flow on both tube-side and shell-side after performing sufficient parametric analysis and even structural optimization with necessary experimental validation. In addition, engineering applications are critically important to find the advantages and disadvantages of this new kind heat exchangers, especially for larger ones since it is hard to perform numerical simulations and experimental measurements of large heat exchangers, and for heat exchangers, results obtained for smaller heat exchanger cannot be readily applied to enlarged ones.

Author Contributions: Conceptualization, Z.W. and C.Q.; methodology, Z.W. and C.Q.; software, Z.W.; validation, Z.W. and C.Q.; formal analysis, C.Q.; investigation, Z.W.; resources, C.Q.; data curation, Z.W.; writing —original draft preparation, Z.W.; writing-review and editing, C.Q.; visualization, Z.W.; supervision, C.Q.; project administration, Z.W.; funding acquisition, C.Q. All authors have read and agreed to the published version of the manuscript.

Funding: This research received no external funding.

Institutional Review Board Statement: Not applicable.

Informed Consent Statement: Not applicable.

Data Availability Statement: Data available on request.

Conflicts of Interest: The authors declare no conflict of interest. 


\section{References}

1. Ambekar, A.S.; Sivakumar, R.; Anantharaman, N.; Vivekenandan, M. CFD simulation study of shell and tube heat exchangers with different baffle segment configurations. Appl. Therm. Eng. 2016, 108, 999-1007. [CrossRef]

2. Ozden, E.; Tari, I. Shell side CFD analysis of a small shell-and-tube heat exchanger. Energy Convers. Manag. 2010, 51, 1004-1014. [CrossRef]

3. He, L.; Li, P. Numerical investigation on double tube-pass shell-and-tube heat exchangers with different baffle configurations. Appl. Therm. Eng. 2018, 143, 561-569. [CrossRef]

4. Xiao, X.; Zhang, L.; Li, X.; Jiang, B.; Yang, X.; Xia, Y. Numerical investigation of helical baffles heat exchanger with different Prandtl number fluids. Int. J. Heat Mass Transf. 2013, 63, 434-444. [CrossRef]

5. Gu, X.; Chen, W.; Fang, Y.; Song, S.; Wang, C.; Wang, Y. Analysis of flow dead zone in shell side of a heat exchanger with torsional flow in shell side. Appl. Therm. Eng. 2020, 180, 115792. [CrossRef]

6. Dong, Q.; Wang, Y.; Liu, M. Numerical and experimental investigation of shellside characteristics for RODbaffle heat exchanger. Appl. Therm. Eng. 2008, 28, 651-660. [CrossRef]

7. Li, N.; Chen, J.; Cheng, T.; Klemeš, J.J.; Varbanov, P.S.; Wang, Q.; Yang, W.; Liu, X.; Zeng, M. Analysing thermal-hydraulic performance and energy efficiency of shell-and-tube heat exchangers with longitudinal flow based on experiment and numerical simulation. Energy 2020, 202, 117757. [CrossRef]

8. Nie, Q.; Tan, W. Fluid Induced Vibration of Shell and Tube Heat Exchanger; China Petrochemical Press: Beijing, China, 2013; pp. 1-3.

9. Ji, J.; Ge, P.; Bi, W. Numerical analysis on shell-side flow-induced vibration and heat transfer characteristics of elastic tube bundle in heat exchanger. Appl. Therm. Eng. 2016, 107, 544-551. [CrossRef]

10. Shaaban, M.; Mohany, A. Flow-induced vibration of three unevenly spaced in-line cylinders in cross-flow. J. Fluids Struct. 2018, 76, 367-383. [CrossRef]

11. Duan, D.; Ge, P.; Bi, W.; Yang, X.; Fu, X.; Yan, K. An empirical correlation for the heat transfer enhancement of planar elastic tube bundle by flow-induced vibration. Int. J. Therm. Sci. 2020, 155, 106405. [CrossRef]

12. Khan, A.; Khushnood, S.; Saqib, N.U.; Shahid, I.S. Numerical simulation of vortex induced vibrations in heat exchanger tube bundle at low reynolds number. J. Nav. Archit. Mar. Eng. 2017, 14, 77-91. [CrossRef]

13. Ishihara, K. Flow Induced Vibration of Shell \& Tube Type Heat Exchanger (1st Report, Understanding of Phenomena). J. Environ. Eng. 2007, 2, 293-302. [CrossRef]

14. Qian, C. A No-Window Baffle Heat Exchanger. China's Patent: ZL 200920271102.1, 27 November 2009.

15. Qian, C.; Dai, L.; Sun, H. A Segmental Large-and-Small-Hole Baffle Heat Exchanger. China's Patent: CN202032923U, 6 April 2011.

16. You, Y.; Fan, A.; Lai, X.; Huang, S.; Liu, W. Experimental and numerical investigations of shell-side thermo-hydraulic performances for shell-and-tube heat exchanger with trefoil-hole baffles. Appl. Therm. Eng. 2013, 50, 950-956. [CrossRef]

17. Wang, D.; Wang, H.; Xing, J.; Wang, Y. Investigation of the thermal-hydraulic characteristics in the shell side of heat exchanger with quatrefoil perforated plate. Int. J. Therm. Sci. 2021, 159, 106580. [CrossRef]

18. Wang, Y.; Dong, Q.; Liu, M. Characteristics of Fluid Flow and Heat Transfer in Shellside of Heat Exchangers with Longitudinal Flow of Shellside Fluid with Different Supporting Structures. In Challenges of Power Engineering and Environment: Proceedings of the International Conference on Power Engineering 2007; Springer Science \& Business Media: Hangzhou, China, 2007; pp. 474-479. [CrossRef]

19. El Maakoul, A.; Laknizi, A.; Saadeddine, S.; El Metoui, M.; Zaite, A.; Meziane, M.; Ben Abdellah, A. Numerical comparison of shell-side performance for shell and tube heat exchangers with trefoil-hole, helical and segmental baffles. Appl. Therm. Eng. 2016, 109, 175-185. [CrossRef]

20. Ma, L.; Wang, K.; Liu, M.; Wang, D.; Liu, T.; Wang, Y.; Liu, Z. Numerical study on performances of shell-side in trefoil-hole and quatrefoil-hole baffle heat exchangers. Appl. Therm. Eng. 2017, 123, 1444-1455. [CrossRef]

21. Sun, H.; Qian, C. Study of the heat transfer and flow resistance of large and small hole (LASH) baffle heat exchanger. Appl. Therm. Eng. 2013, 54, 536-540. [CrossRef]

22. Liu, J.; Qian, C. Comparison of the fluid flow and heat transfer in shell-and-tube heat exchangers with different baffles and tubes: Simulation and experimental studies. Asia-Pac. J. Chem. Eng. 2016, 11, 1051-1059. [CrossRef]

23. Qian, C.; Yang, J. Arc-Tangent Corrugated Tubes. China's Patent: ZL200720178700.5, 3 December 2008.

24. Ji, S.; Yin, T.; Shu, W. Numerical study on vibration characteristics of flow induced of U-tubes. Light Ind. Mach. 2020, 38, 53-58. (In Chinese)

25. Wu, Z.; Qian, C.; Liu, G. Experimental and simulation study on the heat exchanger with conically-corrugated tubes and baffles with holes in different diameters. Press Vessel. Technol. 2021, 9, 1-10. (In Chinese) 